\title{
STUDY ON OVULATION INDUCTION WITH CLOMIPHENE CITRATE, METFORMIN, HUMAN CHORIONIC GONADOTROPIN AND HUMAN MENOPAUSAL GONADOTROPIN IN FEMALE INFERTILITY
}

\author{
Anuradha De Pati1, Selim Akhtar², Nibedita Chattopadhyay33, Susanta Banerjee ${ }^{4}$ \\ ${ }_{1}^{1}$ Associate Professor, Department of Pathology, School of Tropical Medicine, Kolkata, West Bengal, India. \\ ${ }^{2}$ Residential Medical Officer Cum Clinical Tutor, Department of Obstetrics and Gynaecology, Calcutta National Medical College and \\ Hospital, Kolkata, West Bengal, India. \\ 3Professor, Department of Obstetrics and Gynaecology, Cooch Behar Government Medical College and Hospital, Cooch Behar, \\ West Bengal, India. \\ ${ }^{4}$ Professor and HOD, Department of Radiodiagnosis, Calcutta National Medical College and Hospital, Kolkata, West Bengal, India.
}

\begin{tabular}{l}
\hline ABSTRACT \\
BACKGROUND \\
Ovulatory disorders account for about $30-40 \%$ of all causes of female infertility. Normal ovulation requires co-ordination of neuro- \\
endocrinal system at all levels. Clomiphene citrate, human chorionic gonadotropin, human menopausal gonadotropin, metformin \\
are the commonly used drugs for ovulation induction. They are used alone or in combination with ultrasound monitoring. \\
Ovulation is characterized by a decrease in the size of a monitored ovarian follicle and by the appearance of fluid in the cul-de sac \\
by ultrasound. We wanted to evaluate the effects of ovulation inducing agents like ovulation rate (by ultrasound monitoring), \\
viable pregnancy rate ( $\geq 28$ weeks), abortion rate and side effects like multiple pregnancies \& ovarian hyper stimulation syndrome \\
(OHSS) in a case of primary or secondary infertility.
\end{tabular}

\section{METHODS}

Our study was an interventional study and was done to induce ovulation among 100 infertile women having oligo-ovulation or anovulation with clomiphene citrate alone, with metformin alone, with combination of clomiphene citrate \& metformin, with combination of clomiphene citrate \& HCG, with combination of clomiphene citrate, HMG \& HCG. It was conducted at the department of Obstetrics \& Gynecology, Calcutta National Medical College \& Hospital, and Kolkata from February 2017 to August 2018.

\section{RESULTS}

In this study group of 100 cases of infertility, $80 \%$ were primary infertility and $20 \%$ were of secondary infertility and maximum number of cases belong to the age group 26-30 years (55\%). The maximum number $(70 \%)$ of cases presented within 7 years of marriage. In our study it was found that ovulatory response is better with combination of clomiphene \& metformin (62.5\%) than clomiphene alone (53.84\%) or metformin alone (48.57\%). Regarding pregnancy rate, metformin alone (42.85\%) and combination of clomiphene \& metformin (43.75\%) are almost similar in efficacy but both are superior to clomiphene alone (35.38\%). Total rate of ovulation with clomiphene \& HCG was $66.66 \%$ and total rate of conception was 50\%. With clomi phene, HMG \& HCG ovulation rate was approximately $50 \%$ \& conception rate $33.33 \%$. OHSS is an important iatrogenic side effect of ovulation inducing drugs specially clomiphene with HCG \& HMG. In our study, the incidence of multiple pregnancies was 4\% (4 out of 100 cases, among which 3 were twin and one triplet). 3 cases were found with the use of clomiphene citrate alone and one case was found with the use of combination of clomiphene \& metformin. The incidence of pregnancy wastage in my study was $12 \%$ (Total 12 abortions in 100 patients).

\section{CONCLUSIONS}

Total 70 patients conceived out of total 100 patients studied and out of which 97 patients ovulated. Pregnancy rates were maximum with clomiphene with HCG (50\%). Among 70 patients conceived, 12 aborted in early pregnancies during study time \& 58 patients gave birth to term babies. Rate of OHSS and pregnancy wastage was $12 \%$ each. Multiple pregnancies occurred in 4 patients out of 100 patients. So, if there is a correct evaluation of cases, conveying psychological assurance, taking the couple into confidence and providing them a correct medical therapy, we can help them to become mother and have happy family.

\section{KEY WORDS}

Ovulation Induction, Infertility, Clomiphene Citrate, Metformin, Human Chorionic Gonadotropin, Human Menopausal Gonadotropin HOW TO CITE THIS ARTICLE: Pati AD, Akhtar S, Chattopadhyay N, et al. Study on ovulation induction with clomiphene citrate, metformin, human chorionic gonadotropin and human menopausal gonadotropin in female infertility. J. Evolution Med. Dent. Sci. 2019;8(23):1820-1824, DOI: 10.14260/jemds/2019/400

\begin{tabular}{|c|c|}
\hline BACKGROUND & syndrome, $\quad$ hypogonadotropic \\
\hline Infertility is defined as one year of unprotected intercourse & hyperprolactinaemia \& hypothyroidism. \\
\hline without pregnancy. ${ }^{1}$ This condition is further classified as & Induction of ovulation is indicated in - \\
\hline primary infertility and secondary infertility. Normal & 1. Anovulatory infertile women (commonest cause) \\
\hline ovulation requires co-ordination of neuro-endocrinal system & Timing of ovulation in irregularly ovulating women \\
\hline at all levels i.e. central hypothalamic-pituitary axis, the & 3. Oocyte maturation for in-vitro fertilization \\
\hline $\begin{array}{l}\text { feedback signal \& local response within the ovary. An } \\
\text { ovulatory disorders are commonly due to polycystic ovarian }\end{array}$ & $\begin{array}{l}\text { 4. As a test of pituitary or ovarian function. Clomiphe } \\
\text { citrate, human chorionic gonadotropin (HCG), hum }\end{array}$ \\
\hline
\end{tabular}


menopausal gonadotropin (HMG), metformin are the commonly used drugs for ovulation induction. They are used alone or in combination with ultrasound monitoring. Ovulation is documented by monitoring the development of a dominant follicle by ultrasound until ovulation takes place. Ovulation is characterized by a decrease in the size of a monitored ovarian follicle and by the appearance of fluid in the cul-de sac.2,3

Commercially available kits for documenting the LH surge are generally accurate, quick convenient and relatively inexpensive. 4 The least expensive method of confirming ovulation is for the patient to her temperature each morning on a basal body temperature chart. The oral or rectal temperature should be determined before the patient arises, eats or drinks.

\section{METHODS}

Our study was a Interventional study and was done to induce ovulation among 100 infertile women (Sample size taken as per convenience) having oligo-ovulation or anovulation. It was conducted at the department of Obstetrics \& Gynaecology, Calcutta National Medical College \& Hospital, Kolkata from February 2017 to August 2018. The study population was selected from the couples attending the outpatient department. Cases were also selected from those admitted in the in-patient department for evaluation of their infertility status. Infertility status of all couples was evaluated by history from both partners; clinical examination and different routine and specific tests for infertility, so that the cause of their infertility could be detected. Only those couples were undertaken for this study in whom oligo-ovulation or anovulation was suspected. Ovulation was detected by ultrasonography.

\section{Inclusion Criteria}

1. Woman who failed to conceive after staying with her husband at least for 1 year without any contraception

2. Both partner in fertile age group.

\section{Exclusion Criteria}

1. Abnormal semen analysis of the husband

2. Uterus is not morphologically normal and any of the fallopian tubes is not patent by hystero-salpingography or laparoscopic chromopertubation.

3. Patients with functional ovarian cyst, neoplastic ovarian cyst or ovarian failure.

4. Patients with liver disorders, Visual disturbances (blurred or double vision, scotoma and light sensitivity)

5. Patients with hyperprolactinaemia, hypothyroidism, diabetes mellitus.

'Financial or Other Competing Interest': None.

Submission 06-04-2019, Peer Review 25-05-2019,

Acceptance 01-06-2019, Published 10-06-2019.

Corresponding Author:

Dr. Selim Akhtar

Neel Diganta Enclave, Flat No. I-3, $3^{\text {rd }}$ Floor, Block- B,

Sethpukur P. O. + P. S., Barasat-700124,

North 24 Parganas, West Bengal, India.

E-mail: s.akhtar19841984@gmail.com

DOI: $10.14260 /$ jemds $/ 2019 / 400$

\section{(c) (i) $\$$}

6. Patients treated with ovulation inducing drugs in last 3 months.

\section{Aims and Objectives}

To evaluate the following effects of ovulation inducing agents in a case of primary or secondary infertility-

1. Ovulation rate by ultrasound monitoring.

2. Viable pregnancy rate ( $\geq 28$ weeks).

3. Abortion rate.

4. Side effects like multiple pregnancies \& ovarian hyper stimulation syndrome (OHSS)

\section{RESULTS}

Out of the 100 couples studied, primary infertility was found in $80 \%$ and secondary infertility in $20 \%$. Incidence of primary infertility was 4 times than that of secondary infertility.

Most of the cases $(80 \%)$ in our study presented at a younger age group (i.e. 20-30 years). Maximum number of cases were between 26-30 years of age (55 Cases) and next between 20-25 years of age (25 Cases).

In our study the duration of infertility ranged from 2 years to 20 years and it was observed that $70 \%$ of the cases presented within 7 years of infertility.

In $65 \%$ cases, therapy for ovulation induction used was clomiphene alone. In $35 \%$ cases, metformin was given alone. $48 \%$ patients were given clomiphene with metformin in whom ovulation did not occur with clomiphene alone or metformin alone. Clomiphene with HCG was given in $18 \%$ patients in whom ovulation fails to occur with clomiphene with metformin. Rest $6 \%$ were given clomiphene with HCG \& HMG in whom ovulation did not occur with clomiphene with HCG.

Table I shows that 65 patients were started with $50 \mathrm{mg}$ clomiphene; in whom ovulation did not occur (48 Patients), they were given $100 \mathrm{mg}$ clomiphene. $150 \mathrm{mg}$ clomiphene given in those (38 Patients) who did not ovulate with $100 \mathrm{mg}$ dose.

Total ovulation rate with clomiphene were $53.84 \%$ and pregnancy rate were $35.38 \%$.

With clomiphene, viable pregnancy rate was $29.23 \%(19$ cases), spontaneous abortion rate were $06.15 \%$ ( 4 cases), rate of multiple pregnancy were $04.61 \%$ (3 cases) \& rate of OHSS were $06.15 \%$ ( 4 cases).

Only metformin was given to 35 patients for one month; in whom ovulation did not occur metformin was continued for one more month and it was continued for three months in those who did not ovulate after two months of the drug. Total ovulation rate was $48.57 \%$ and pregnancy rate was $42.85 \%$ (Table II)

With metformin alone the viable pregnancy rate was $34.28 \%$ ( 12 cases); rate of spontaneous abortion was $08.57 \%$ (3 cases); no cases of multiple pregnancy and OHSS found.

Out of 48 patients treated with clomiphene and metformin, 30 patients ovulated \& 21 patients conceived. Maximum number of ovulations occurred in 3rd cycle. (Table III). The viable pregnancy rate was $37.50 \%$ (18 cases); spontaneous abortion rate was $06.25 \%$ (3 cases); rate of multiple pregnancy and OHSS were $02.08 \%$ ( 1 case) and $04.16 \%$ ( 2 cases) respectively.

Ovulation \& conception rate was highest in $2^{\text {nd }}$ cycle where $150 \mathrm{mg}$ clomiphene was used from $2^{\text {nd }}$ day of 
menstruation for 5 days \& USG done for ovulation profile on $10^{\text {th }}$ day onwards till the follicular size was of $18 \mathrm{~mm} \&$ then Inj HCG (5, $000 \mathrm{IU})$ given IM.

With clomiphene \& HCG total rate of ovulation were $66.66 \%$ and total rate of conception were $50 \%$ (Table IV). With clomiphene \& HCG rate of viable pregnancy were $38.88 \%$ (7 cases), rate of spontaneous abortion were $11.11 \%$ ( 2 cases), rate of OHSS were $22.22 \%$ ( 4 cases). No case of multiple pregnancies found.

Clomiphene, HCG and HMG were prescribed only in 6 cases and for three cycles as it was cost effective to monitor the cases. Out of these patients 3 ovulated \& 2 conceived. (Table V). Rate of viable pregnancy were $33.33 \%$ (2 cases) \& rate of OHSS were $33.33 \%$ ( 2 cases). No case of multiple pregnancy and spontaneous abortion found.

Efficacy and complications of different ovulation inducing agents is summarized in table VI.

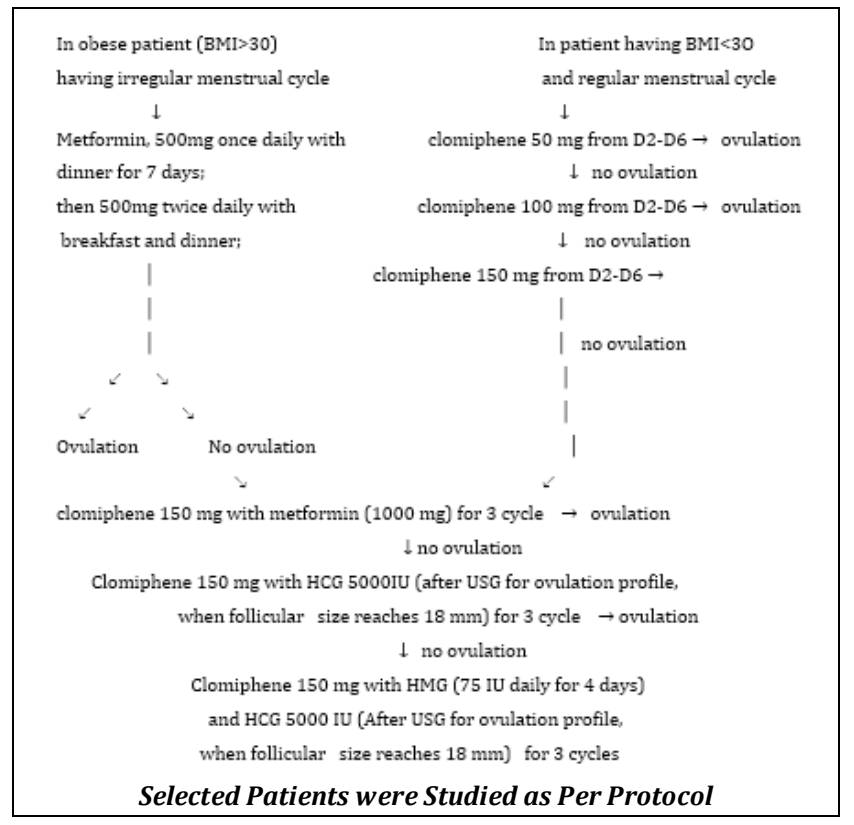

\begin{tabular}{|c|c|c|c|c|c|}
\hline 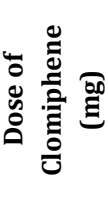 & 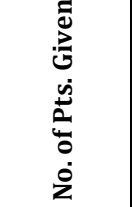 & 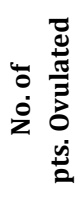 & 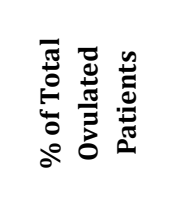 & 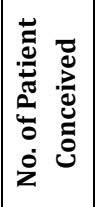 & 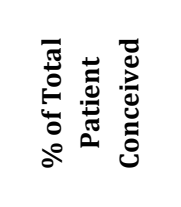 \\
\hline 50 & 65 & 17 & $26.15(17 / 65)$ & 12 & $18.48(12 / 65)$ \\
\hline 100 & $48(65-17)$ & 10 & $20.83(10 / 48)$ & 06 & $12.50(06 / 48)$ \\
\hline 150 & $38(48-10)$ & 08 & $21.05(08 / 38)$ & 05 & $13.15(05 / 38)$ \\
\hline Total & 65 & 35 & $53.84(35 / 65)$ & 23 & $35.38(23 / 65)$ \\
\hline \multicolumn{6}{|c|}{ Table I. Su } \\
\hline
\end{tabular}

\begin{tabular}{|c|c|c|c|c|c|}
\hline 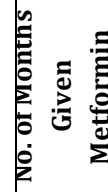 & 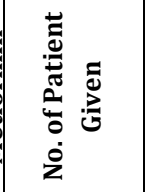 & 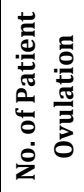 & 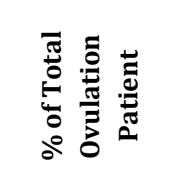 & 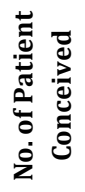 & 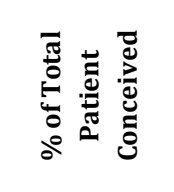 \\
\hline 1 & 35 & 08 & $22.85(08 / 35)$ & 06 & $17.14(06 / 35)$ \\
\hline 2 & $27(35-08)$ & 05 & $18.51(05 / 27)$ & 05 & $18.51(05 / 27)$ \\
\hline 3 & $22(27-05)$ & 04 & $18.18(04 / 22)$ & 04 & $18.18(04 / 22)$ \\
\hline Total & 35 & 17 & $48.57(17 / 35)$ & 15 & $42.85(15 / 35)$ \\
\hline \multicolumn{6}{|c|}{ Table II. Summary of Efficacy of Metformin } \\
\hline
\end{tabular}

\begin{tabular}{|c|c|c|c|c|c|}
\hline 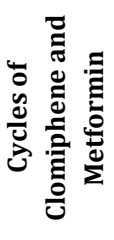 & 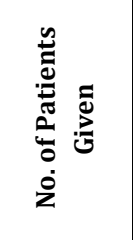 & 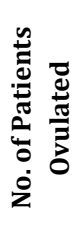 & 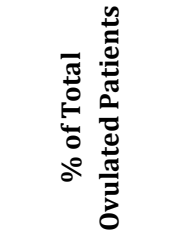 & 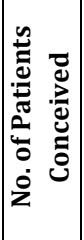 & 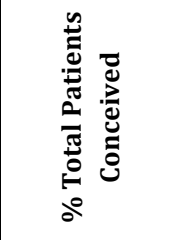 \\
\hline $1^{\text {st }}$ & 48 & 08 & $16.66(08 / 48)$ & 05 & $10.41(05 / 48)$ \\
\hline $2^{\text {nd }}$ & 40 (48-08) & 08 & $20.00(08 / 40)$ & 06 & $15.00(06 / 40)$ \\
\hline $3^{\text {rd }}$ & $32(40-08)$ & 14 & $43.75(14 / 32)$ & 10 & $31.25(10 / 32)$ \\
\hline Total & 48 & 30 & $62.50(30 / 48)$ & 21 & \begin{tabular}{|l|}
$43.75(21 / 48)$ \\
\end{tabular} \\
\hline
\end{tabular}

\begin{tabular}{|c|c|c|c|c|c|}
\hline 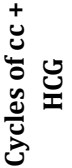 & $\begin{array}{l}\dot{0} \\
\stackrel{0}{0} \\
\dot{0} \\
\dot{0} \\
\dot{z}\end{array}$ & 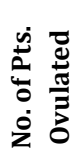 & 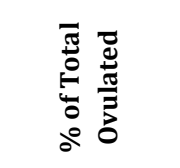 & 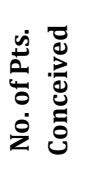 & 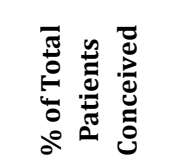 \\
\hline $1^{\text {st }}$ & 18 & 05 & $27.77(05 / 18)$ & 03 & $16.66(03 / 18)$ \\
\hline $2^{\text {nd }}$ & $13(18-05)$ & 05 & $38.46(05 / 13)$ & 04 & $30.76(04 / 13)$ \\
\hline $3^{\text {rd }}$ & $08(13-05)$ & 02 & $25.00(02 / 08)$ & 02 & $25.00(02 / 18)$ \\
\hline Total & 18 & 12 & $66.66(12 / 18)$ & 09 & $50.00(09 / 18)$ \\
\hline \multicolumn{6}{|c|}{ Table IV. Summary of Efficacy of Clomiphene with HCG } \\
\hline
\end{tabular}

\begin{tabular}{|c|c|c|c|c|c|}
\hline 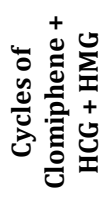 & 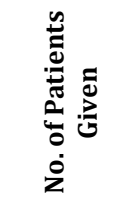 & 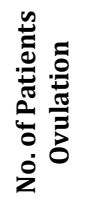 & 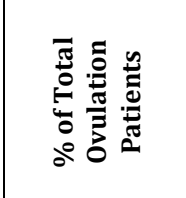 & 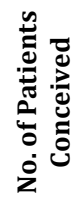 & 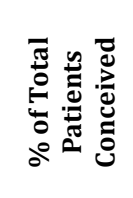 \\
\hline $1^{\text {st }}$ & 06 & 00 & 00 & 00 & 00 \\
\hline $2^{\text {nd }}$ & $06(06-00)$ & 01 & $16.66(01 / 06)$ & 00 & 00 \\
\hline $3^{\text {rd }}$ & 05 (06-01) & 02 & $40.00(02 / 05)$ & 02 & $40(02 / 05)$ \\
\hline Total & 06 & 03 & $50.00(03 / 06)$ & 02 & $\begin{array}{c}33.33 \\
(02 / 06)\end{array}$ \\
\hline
\end{tabular}

\begin{tabular}{|c|c|c|c|c|c|}
\hline & 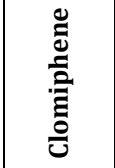 & 部 & 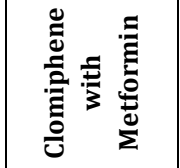 & 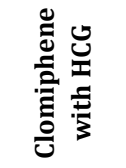 & 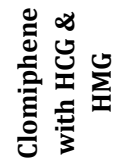 \\
\hline & $\%$ & $\%$ & $\%$ & $\%$ & $\%$ \\
\hline $\begin{array}{l}\text { No. of } \\
\text { patient } \\
\text { given }\end{array}$ & $\left.\begin{array}{c}6565 \\
(65 / 100)\end{array}\right)$ & $\begin{array}{c}3535 \\
(35 / 100)\end{array}$ & $\begin{array}{c}48(30+18) 48 \\
(48 / 100)\end{array}$ & $\begin{array}{c}1818 \\
(18 / 100)\end{array}$ & $\begin{array}{c}0606 \\
(06 / 100)\end{array}$ \\
\hline Ovulation & \begin{tabular}{|c|}
3553.84 \\
$(35 / 65)$
\end{tabular} & & & & \\
\hline Conception & 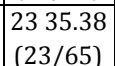 & $\begin{array}{l}1542 \\
15 /\end{array}$ & $\begin{array}{l}214 \\
(21 /\end{array}$ & $\begin{array}{l}095 \\
09 /\end{array}$ & $\begin{array}{l}0233.33 \\
(02 / 06)\end{array}$ \\
\hline $\begin{array}{c}\mathrm{VP} \\
(>28 \mathrm{wks} .)\end{array}$ & \begin{tabular}{|l|l|}
1929.23 \\
$(19 / 65)$
\end{tabular} & $\begin{array}{l}1234.28 \\
(12 / 35)\end{array}$ & $\begin{array}{l}1837.50 \\
(18 / 48)\end{array}$ & $\begin{array}{l}0738.88 \\
(07 / 18)\end{array}$ & $\begin{array}{l}0233.33 \\
(02 / 06)\end{array}$ \\
\hline \multicolumn{6}{|c|}{ Complications } \\
\hline OHSS & $\begin{array}{c}0406.15 \\
(04 / 65)\end{array}$ & $\begin{array}{l}\text { NIL } \\
\text { NIL }\end{array}$ & $\begin{array}{l}0204.16 \\
(02 / 48)\end{array}$ & $\begin{array}{c}0422.22 \\
(04 / 18)\end{array}$ & $\begin{array}{l}0233.33 \\
(02 / 06)\end{array}$ \\
\hline MP & \begin{tabular}{|c|}
0304.61 \\
$03 / 65)$
\end{tabular} & $\begin{array}{l}\text { NIL } \\
\text { NIL }\end{array}$ & $\begin{array}{l}0102.08 \\
(01 / 48)\end{array}$ & $\begin{array}{l}\text { NIL } \\
\text { NIL }\end{array}$ & $\begin{array}{l}\text { NIL } \\
\text { NIL }\end{array}$ \\
\hline SA & $\begin{array}{c}0406.15 \\
(04 / 65)\end{array}$ & $\begin{array}{l}0308.57 \\
(03 / 35)\end{array}$ & $\begin{array}{l}0306.25 \\
(03 / 48)\end{array}$ & $\begin{array}{l}0211.11 \\
(02 / 100)\end{array}$ & $\begin{array}{l}\text { NIL } \\
\text { NIL }\end{array}$ \\
\hline \multicolumn{6}{|c|}{$\begin{array}{c}\text { Table VI. Summary of Efficacy \& Complications of Different } \\
\text { Ovulation Inducing Agents. }\end{array}$} \\
\hline \multicolumn{6}{|c|}{$\begin{array}{l}\text { BMI= Body mass index, } \mathrm{CC}=\text { Clomiphene citrate, } \mathrm{HCG}=\text { Human chorionic } \\
\text { gonadotropin, HMG= Human menopausal gonadotropin, VP= Viable } \\
\text { Pregnancy, OHSS= Ovarian Hyper stimulation Syndrome, MP= Multiple } \\
\text { Pregnancy, } \mathrm{SA}=\text { Spontaneous Abortion }\end{array}$} \\
\hline
\end{tabular}




\section{DISCUSSION}

In this study group of 100 cases of infertility $80 \%$ were primary infertility and $20 \%$ were of secondary infertility and maximum number of cases belong to the age group 26-30 years (55\%). We are well acquainted with the social customs of our country which favour early marriage \& quick childbearing. These accounts for the high number of cases were in young age group.

The maximum number (70\%) of cases presented within 7 years of marriage. Mean duration of infertility was 5 years whereas in cases of secondary infertility the duration was more. Study by WHO (Dec. 1980 to Sept. 1983 in the university clinic of Kandang Kerban Hospital) reported 3.2 years was the duration of infertility which is less than our study group. This can be explained with reference to the social custom \& beliefs of the society.

So, in our study it was found that ovulatory response is better with combination of clomiphene \& metformin than clomiphene alone or metformin alone which is similar to the result of the study done by Zain MM et al in 20095 . We found that the ovulatory response was least with metformin alone.

Regarding pregnancy rate, metformin alone and combination of clomiphene \& metformin are almost similar in efficacy but both are superior to clomiphene alone.

In our study 18 patients were treated with clomiphene with HCG (In whom ovulation failed to occur even with clomiphene with metformin). ) Total rate of ovulation with clomiphene \& HCG were $66.66 \%$ and total rate of conception were $50 \%$. Ovulation \& conception rate was highest in $2^{\text {nd }}$ cycle where $150 \mathrm{mg}$ clomiphene was used.

In our study 6 patients were treated with clomiphene with HMG \& HCG and ovulation rate was approximately 50\% \& conception rate $33.33 \%$. OHSS is an important iatrogenic side effect of ovulation inducing drugs specially clomiphene, HCG \& HMG.

The reported incidence of OHSS is highly variable according to different studies because various classifications are used. Furthermore, these studies relate to very different clinical situations such ovulation induction using gonadotrophins or clomiphene citrate, or ovarian stimulation during IVF, which are not comparable in terms of therapeutic goals and strategies. ESHRE report on ART in Europe in 2004 found an incidence of OHSS of $1.2 \%$ of all stimulated cycles, using register data from 25/29 countries. UK contributed 635 cases from 32,632 cycles (1.94\%). ${ }^{6}$ In our study the total rate of OHSS is $12 \%$ (Total 12 cases among 100 patients). 4 cases found in clomiphene only treated patient, 2 cases found in patients who received clomiphene with metformin, 2 cases found in patients treated with clomiphene with HMG with HCG. Maximum incidence found in patients receiving clomiphene with HCG (4 out of 18).

The administration of drugs that induce ovulation to treat infertile couples has become more frequent in the last decade. Such drugs enhance the probability of multiple pregnancy and have been considered responsible for the increase in multiple births observed in recent years in some countries. In our study the incidence of multiple pregnancies was $4 \%$ ( 4 out of 100 cases, among which 3 were twin and one triplet). 3 cases found with the use of clomiphene citrate alone and one case found with the use of combination of clomiphene \& metformin. This incidence was lower than other available studies $^{7}$

The incidence of pregnancy wastage in my study was $12 \%$ (Total 12 abortions in 100 patients) which was much lower than other reported incidences.8-11 This may be due to better evaluation of infertility cases.

\section{CONCLUSIONS}

Total 70 patients conceived out of total 100 patients studied and out of which 97 patients ovulated. Pregnancy rates were maximum with clomiphene with HCG (50\%).

Among 70 patients conceived, 12 aborted in early pregnancies during study time. 58 patients gave birth to term babies. So, out of 100 patients studied, the viable pregnancy rates were $58 \%$.

Among the complications of ovulation inducing drugs in my study, maximum evidence were both OHSS and pregnancy wastage; rate of each was $12 \%$. The other is multiple pregnancies which occurred in 4 patients out of 100 patients (4\%). The commonest type of multiple pregnancy was twin pregnancy ( 3 out of 4). Only one case of triplet pregnancy was found. Out of 12 cases of OHSS, 11 were mild cases and one was severe for which she was kept hospitalised for careful observation and treated with conservative management.

So, if there is correct evaluation of cases, by conveying psychological assurance, taking the couple into confidence and providing them a correct medical therapy, we can help them to become mothers and have happy families.

\section{REFERENCES}

[1] Berek JS. Berek \& Novak's Gynaecology. 15th edn. Philadelphia, PA, 19103 USA: Lippincott Williams \& Wilkins 2012.

[2] Kerin JF, Edmonds DK, Warnes GM, et al. Morphological \& functional relations of Graafian follicle growth to ovulation in women using ultrasonic, laparoscopic and biochemical measurements. $\mathrm{Br} \mathrm{J}$ Obstet Gynaecol 1981;88(2):81-90.

[3] O’Herlihy C, De Crespigny LC, Lopata A, et al. Preovulatory follicular size: a comparison of ultrasound and laparoscopic measurements. Fertil Steril 1980;34(1):24-6.

[4] Elkind-Hirsch K, Goldzieher JW, Gibbons WE, et al. Evaluation of the OvuSTICK urinary luteinizing hormone kit in normal and stimulated menstrual cycles. Obstet Gynecol 1986;67(3):450-3.

[5] Zain MM, Jamaluddin R, Ibrahim A, et al. Comparison of clomiphene citrate, metformin or the combination of both for first-line ovulation induction, achievement of pregnancy and live birth in Asian women with polycystic ovary syndrome: a randomized controlled trial. Fertil Steril 2009;91(2):514-21.

[6] Andersen AN, Goossens V, Ferraretti AP, et al. Assisted reproductive technology in Europe, 2004: results generated from European Registers by ESHRE. Hum Reprod 2008;23(4):756-71.

[7] Corchia C, Mastroiacovo P, Lanni R, et al. What proportion of multiple births are due to ovulation induction? A register-based study in Italy. Am J Public Health 1996;86(6):851-4. 


\section{Jemds.com}

[8] Gray RH, Wu LY. Subfertility and risk of spontaneous abortion. Am J Publ Health 2000;90(9):1452-4.

[9] Schindler AE. Moglichkeiten der Diagnostik und Therapie mit Clomifen. Frauenarzt 1990;31:253-70.

[10] Jakubowicz DJ, Iuorno MJ, Jakubowicz S, et al. Effects of metformin on early pregnancy loss in the Polycystic ovary syndrome. J Clin Endocrinol Metab 2002;87(2):524-9.

\section{Original Research Article}

[11] Rai R, Backos M, Rushworth F, et al. Polycystic ovaries and recurrent miscarriage -- a reappraisal. Hum Reprod 2000;15(3):612-5. 